\title{
An Analysis of Relative Structure on Causes of Executive Turnover
}

\author{
Qiansheng Zhang, Jing Li * \\ Quality Development institute \\ Kunming University of Science and Technology \\ Kunming, china \\ china.254201056@qq.com
}

\author{
Quanrui Song \\ Faculty of economics \\ Chiangmai University \\ Chiangmai, Thailand
}

\begin{abstract}
Based on the theory and method of system engineering, the paper establishes the interpretive structural modeling of causes of executive turnover with the method of interpretive structural modeling. With this model, the paper reveals the relative structure and the interrelationships among 14 cause elements, and finds out the root causes of influence executive turnover. Finally, we put forward some corresponding countermeasure and suggestion for the enterprises with executives leaving the company, so as to avoid the loss caused by the separation of executives.
\end{abstract}

Keywords-Executive turnover; Cause of turnover; Interpretive structural modeling

\section{INTRODUCTION}

In recent years, there have been frequent incidents such as "the tide of senior executives turnover," "storm of executives quitting," and "absence of executives." The phenomenon of executive turnover will inevitably cause huge losses to enterprises, such as the compelled revision of business strategies and the potential leakage of business secrets, which will directly affect the operation and development of enterprises [1]. Therefore, the fundamental reasons for executive turnover have become the hot topic between business circles and academia. At present, the mainstream among studies is to adopt questionnaires and empirical methods to analyze the hazards, causes, and corresponding countermeasures of the executive turnover [2-8], and there's relatively rare papers using the systematic method. Since the number of causes of executive turnover is large and there exists multiple correlation among the causes, such as the lack of internal incentive mechanisms within the company which makes the outside attractions appealing for the senior executives. Based on the system perspective, the causes for executive turnover is regarded as a system in this paper. By using system engineering theories and methods, we can construct an explanatory structural model of the causes for executive turnover and clarify the relationship structure and mutual influence relationship among the causes, then identify the fundamental causes which can provide some references for enterprises to formulate countermeasures to avoid the executive turnover.

\section{CONSTRUCTION Of InTERPRETIVE STRUCTURAL MOdEL For THe CAUSEs OF EXECUTIVE TURNOVER}

\section{A. Introduction of Interpretive Structural Model}

The Interpretive Structural Modeling (ISM) was proposed by J. Warfield in the United States in 1973 as a method to analyze complex social economic system problems. By decomposing a complex system into several subsystems, professional practical experience and knowledge, as well as the help of the computer, the ISM will eventually form a multilevel hierarchical structure model [9].

ISM is a conceptual model. It can transform ambiguous thoughts and opinions into intuitive models with good structural connection. Therefore, it is widely applied to run the systematic analysis to energy and other international issues to regional economic development, enterprises, and even individual-scale ones [9]. It is particularly applicable to systematic analysis with many variables, complex relationships, and unclear structures, and can also be used for ranking schemes [9].

\section{B. Determination of Causes of Executive Turnover}

The key problem studied in this paper is "executive turnover", $\mathrm{S}_{0}$. Through the analysis of previous research, the reasons for the executive turnover are classified as the internal and external factors of the China's listed enterprise, and the executives themselves. Considering the factors, the final classification of the 14 main factors affecting the turnover of senior executives are: irrational distribution of corporate powers and responsibilities[4] $\mathrm{S}_{1}$, absence of regulation and supervision of senior executives[5] 2, unreasonable compensation system $[4][6][10] \mathrm{S}_{3}$, lack of internal incentive mechanisms[5-6][11] $\mathrm{S}_{4}$, inadequacy of corporate regulations $[7] \mathrm{S}_{5}$, external influence or attraction[ $[4] \mathrm{S}_{6}$, lower payment than counterparts[7][12][13][14][15] $\mathrm{S}_{7}$, lack of motivation[4][11] $\mathrm{S}_{8}$, personal reasons[3][5][13][16][17] $\mathrm{S}_{9}$, discordance between career planning and enterprise development status[8] $\mathrm{S}_{10}$, salary standards is lower than personal expectations[4][11][12][14][16] $\mathrm{S}_{11}$, no potential on personal development[6][16] $\mathrm{S}_{12}$, discordant between enterprise culture and personal lifestyle[6][17][18] $\mathrm{S}_{13}$ and lack of interest about current work[4][7][17] $\mathrm{S}_{14}$. 


\section{Determination of Multiple Correlation Between Causes}

In order to clearly analyze the impact of each factor on turnover of senior executives, we establish an explanatory structural model. Firstly, it is necessary to clarify the mutual correlation among the factors. The criteria for determining the correlation are as follows:

1) if $S_{i}$ has influence on $S_{j}$, then the value of the corresponding place is 1 , otherwise $0 .(i, j=0,1,2, \cdots, 14)$

2) for the factors which have the mutual correlation, choose the factors which contribute more influence.

In this paper, we select five experts related to the study of executive turnover, and use the method of brainstorming to repeatedly discuss the relationships among the 14 factors in $\mathrm{B}$. Then, we can build the adjacency matrix $A$.

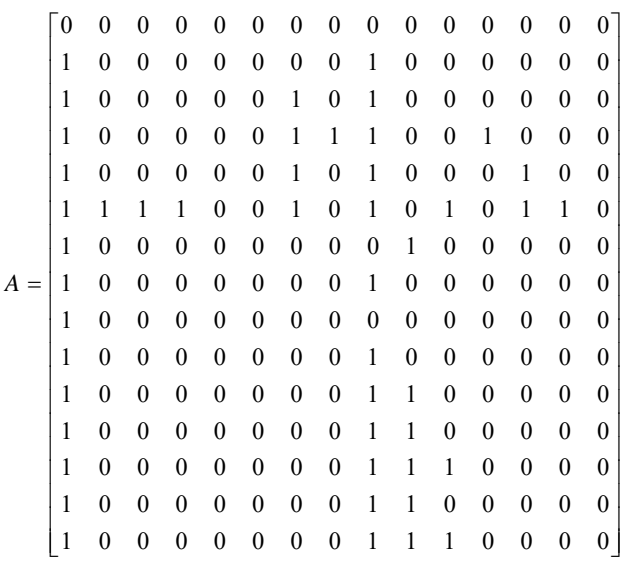

\section{Dividing The Correlation among Various Factors}

It's easily to get the reachability matrix $M=(A+I)^{3}$ by adjacency matrix $A$, where $I$ is 15 order identity matrix.

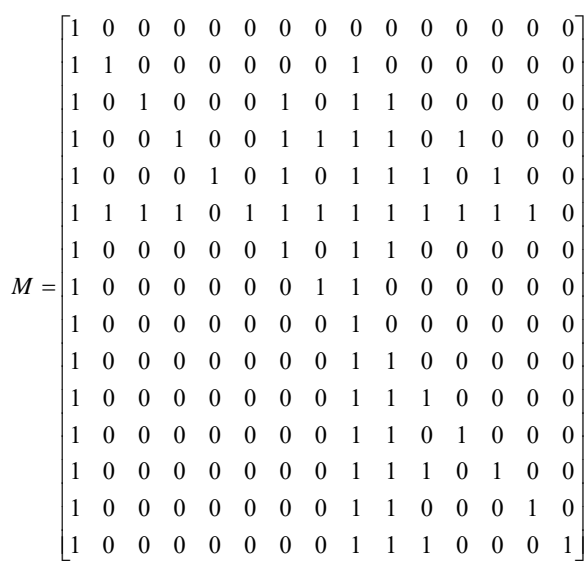

As shown in Table I, from $\mathrm{M}$, we can get the reachable set $R\left(S_{i}\right)$, antecedent set $A\left(S_{i}\right)$ and their intersection $R\left(S_{i}\right) \cap A\left(S_{i}\right)$ of the causes of executive turnover.
TABLE I. 1ST CLASS OF REACHABLE AND ANTECEDENT SET

\begin{tabular}{|c|c|c|c|}
\hline$S_{i}$ & $R\left(S_{i}\right)$ & $A\left(S_{i}\right)$ & $R\left(S_{i}\right) \cap A\left(S_{i}\right)$ \\
\hline$S_{0}$ & 0 & $0,1,2, \ldots, 14$ & 0 \\
\hline$S_{1}$ & $0,1,8$ & 1,5 & 1 \\
\hline$S_{2}$ & $0,2,6,9$ & 2,5 & 2 \\
\hline$S_{3}$ & $0,3,6,7,8,9,11$ & 3,5 & 3 \\
\hline$S_{4}$ & $0,4,6,8,9,10,12$ & 4 & 4 \\
\hline$S_{5}$ & $\begin{array}{c}0,1,2,3,5,6,7,8,9,10,1 \\
1,12,13\end{array}$ & 5 & 5 \\
\hline$S_{6}$ & $0,6,8,9$ & $2,3,4,5,6$ & 6 \\
\hline$S_{7}$ & $0,7,8$ & $3,5,7$ & 7 \\
\hline$S_{8}$ & 0,8 & $1,2, \ldots, 14$ & 8 \\
\hline$S_{9}$ & $0,8,9$ & $\begin{array}{c}2,3,4,5,6,9,10,11 \\
, 12,13,14\end{array}$ & 9 \\
\hline$S_{10}$ & $0,8,9,10$ & $4,5,10,12,14$ & 10 \\
\hline$s_{11}$ & $0,8,9,11$ & $3,5,11$ & 11 \\
\hline$S_{12}$ & $0,8,9,10,12$ & $4,5,12$ & 12 \\
\hline$S_{13}$ & $0,8,9,13$ & 5,13 & 13 \\
\hline$S_{14}$ & $0,8,9,10,14$ & 14 & 14 \\
\hline
\end{tabular}

According to Table I, we can find out the factor causes for S0 which are combined into the set of first factor causes set, namely $L_{1}=\left\{S_{0}\right\}$.

Cancelling the corresponding columns and rows of $\mathrm{S}_{0}$ in $\mathrm{M}$, then we can get the $R\left(S_{i}\right), A\left(S_{i}\right), \quad R\left(S_{i}\right) \cap A\left(S_{i}\right)$. The factor causes $\mathrm{S}_{8}$ which satisfy the condition $R\left(S_{i}\right) \cap A\left(S_{i}\right)=R\left(S_{i}\right)$ are combined into the set of second factor causes set, namely $L_{2}=\left\{S_{8}\right\}$. Similarly, we can get the $L_{3}=\left\{S_{1}, S_{7}, S_{9}\right\}, L_{4}=\left\{S_{6}, S_{10}, S_{11}, S_{13}\right\}, L_{5}=\left\{S_{2}, S_{3}, S_{12}, S_{14}\right\}$ and $L_{6}=\left\{S_{4}, S_{5}\right\}$.

\section{E. Construction of The Interpretive Structural Modeling}

According to the previous section, we can construct the ISM which is shown in Fig. 1.

\section{Correlation Analysis Of CAuse Factors}

The ISM model for executive turnover (Fig. 1) shows that the causes of the departure of senior executives constitute a multi-level hierarchical structure with six levels. This section will analyze the causes of executive turnover ISM model. 


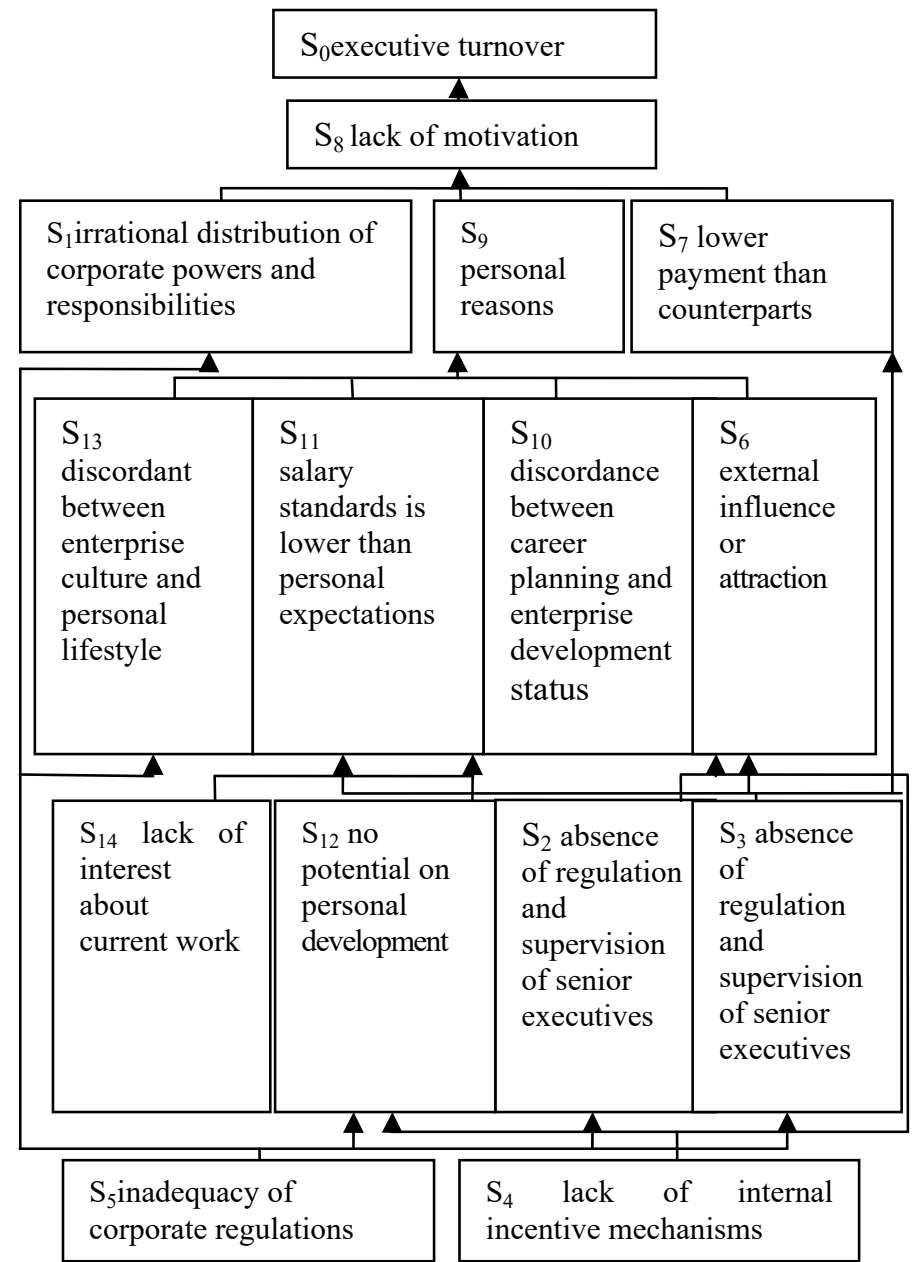

Fig. 1. ISM for executive turnover.

Through the overall analysis of the model, we can see that the lack of interest in current work, inadequacy of corporate regulations, and lack of internal incentive mechanisms are the important reasons for the senior executive turnover. Among them, the factor of executives who are not interested in current work is uncontrollable factor while other two are controllable factors. For controllable factors, companies should emphasize management and prevention to avoid these controllable factors lead to the risk of executives turnover.

Through the hierarchical analysis of the correlation structure of the model, we can see that:

Level 1 has one element, the executive turnover. This is the ultimate result of the reasons for the executive turnover, that is, all the causes may eventually lead to the departure of executives.

There is one element in Level 2, the lack of motivation. It is the direct and main reason for the Level 1 element. Among all the reasons for the executive turnover, the lack of motivation is particularly prominent in the direct reason for the departure of senior executives. It provides companies with an early warning of the executive turnover when executives are lack enthusiasm.

Level 3 has three elements, irrational distribution of corporate powers and responsibilities, personal reasons, and lower payment than counterparts. All these factors directly lead to the lack of motivation which is contained in the second-level factor. These are indirect reasons for executive turnover. Among them, the irrational distribution of powers and responsibilities is the factor that directly influences the factors of the sixth level (the fundamental cause of the departure of senior executives). That is, this factor is also the basic reason that affects the lack of motivation of senior executives.

Level 4 has four elements, discordant between enterprise culture and personal lifestyle, salary standards is lower than personal expectations, discordance between career planning and enterprise development status, and external influence or attraction. All these factors are directly related to Level 3 . The influence of factors on personal reasons has indirect impact on the departure of senior executives and it's an indirect cause of the departure of senior executives. Furthermore, personal reasons have huge impact on personal motivation which may increase the probability for executive turnover.

Level 5 has four elements, lack of interest about current work, no potential on personal development, absence of regulation and supervision of senior executives and the unreasonable compensation system. These factors are directly impact the level 4 factors and indirectly impact the executive turnover. Particularly, as we can see from Level 5, there is no cause factor at Level 6 that has an impact on "lack of interest about current work" which indicates that it has a weak relation to lack of internal incentive mechanisms and inadequacy of corporate regulations. It coincides with common sense. Even if the regulations and payment are relatively good, employees are likely to quit the job to find a more suitable job if they are not interest in the current ones.

Level 6 has two elements, lack of internal incentive mechanisms and inadequacy of corporate regulations. These are the most fundamental reason for the executive turnover. Therefore, these two factors are the starting points for effectively solving the issue of executive turnover.

\section{CONCLUSION AND SUGgestion}

Executives play an important role in company management, and the departure of executives will undoubtedly make a negative impact on the company's production and operations. Therefore, we introduce the ISM by establishing reasons executive turnover, then analyze the relationship structure and mutual correlation among the factors of several isolated samples, and find out the fundamental reasons that affect the departure of senior executives, lack of internal incentive mechanisms and inadequacy of corporate regulations. Since these two fundamental causes contain a relatively large scope, we will propose some corresponding suggestions and countermeasures for the causes as follows.

\section{A. Improve Corporate Management Rules and Regulation}

The inadequacy of corporate regulations directly affects the absence of regulation and supervision of senior executives, irrational distribution of corporate powers and responsibilities, unreasonable compensation system, and the lack of a compensation system, humanistic environment and so on. Firstly, it is possible to strengthen the supervisory constraints 
on senior management by following the principle of reasonableness and properness. Using rewards and punishments system like specifying the penalty executives need to pay when they voluntary leave the company while signing the contract with them is proved to be workable. Secondly, company must balance the powers and responsibilities and allocate them appropriately. To be specific, issuing the job descriptions may help a lot. on the one hand it ensures that the powers held by senior executives are coordinate with their responsibilities, and on the other hand, they clarify the powers and responsibilities. Additionally, follow the principle of fairness and design a reasonable compensation system. Establish an internal and external fair compensation system so that executives can get the reasons payment by their hard working, contributions and performances. At the same time, there should not exist difference among internal employees with the same or equivalent competencies, and compensation should consistent with the compensation standards of the same industry in the region. Last but not least, it's important to implement the people-oriented principle and create a harmonious humanistic environment. By creating a harmonious corporate culture and cultivating employees' awareness of unity and cooperation, employees can get mutual respect and understanding, more willing to offer help and a more pleasant working environment.

\section{B. Establish Appropriate Incentive Mechanism}

The absence of incentive mechanisms in enterprises directly leads to the problems of external influence or attraction and no potential on personal development. Therefore, we suggest the company to use both material incentives and spiritual incentives to solve the problems. For material incentives, enterprises may implement incentives such as performance compensation, equity incentives, and implement flexible benefits such as education and training allowances, tourism welfare plans, children's education support plans, and children's medical insurance and so on. For spiritual incentives, it's helpful to explain to executives with details about how they can get their opportunities of promotion, training, further education, overseas dispatch and flexible working hours.

Previous suggestions and countermeasures provide a reference for enterprises to retain their talented and outstanding executives and inspire their enthusiasm of work. In addition, this paper also shows that in the case of a relatively adequate corporate regulation system, the incentive mechanism is an important way for companies to effectively avoid the executive turnover.

\section{REFERENCES}

[1] Y.D. Shen, C. Xu, and L. H. Jiao, "Empirical study on the information content of group dimission behaviors of senior executives in financial distress early warning," Exploration of economic issues, vol. 2, pp. 7580, 2011.

[2] A. Iqbal, "Employee turnover: causes, consequences and retention strategies in the saudi organizations," The Business Review, vol. 2, pp. 275-281, 2010.

[3] C. O. Trevor and A.J. Nyberg, "Keeping your headcount when all about you are losing theirs: Downsizing, voluntary turnover rates, and the moderating role of hr practices," Academy of Management Journal, vol. 51, pp. 259-76, 2008.

[4] J.L. Price, "Reflections on the determinants of voluntary turnover," International Journal of Manpower, vol. 22, pp. 600-624, 2001.

[5] R.S. Ye and Y.H. Guo, Empirical research on the information content of group dimission behaviors of senior executives in financial distress early warning Systems engineering, 2003, pp. 87-90.

[6] J.G. Wei, Empirical analysis on resignation intention of knowledgebased employees in high-tech enterprises, Technological progress and countermeasures, 2009, pp. 177-179.

[7] J.J. Gu and F.H. Xie, Empirical research on the reasons for employee dimission in small and medium-sized private manufacturing enterprises , Economics, 2007, pp. 101-103.

[8] Q.H. Weng and Y.M. Xi, Career growth and dimission tendency: the regulatory role of occupational commitment and perceived opportunity, Tianjin: nankai management review, 2010, pp. 119-130,

[9] S.J. Bai, System engineering. Beijing: electronic industry press, 2009

[10] A.M. Qian and D.L. Zhi, "Fair result or fair process?-- empirical analysis of employee dimission based on salary incentive," Economic and management research, vol. 2014(9), pp. 101-109.

[11] Z.J. Gao, "Research on innovative talent flow: based on empirical evidence of turnover of top executives in gem," Management modernization, vol. 2015(6), pp. 85-87.

[12] B.X. Li and B.S. Yao, "Analysis and response study on the reasons for executives' resignation in China's gem listed companies," Qinghai social science, vol. 2013(1), pp. 53-56.

[13] X.H. Wei, Y.M. Liu, and X.L. Che, "A cross-level study on factors influencing the turnover of executives in Chinese listed enterprises," Management science, vol. 2013(6), pp. 71-82.

[14] A. Wu, "Analysis on non-ferrous metal executives' dimission factors ," Gold, vol. 2016(10), pp. 1-4.

[15] Y.Y. Wang, Analysis on motivation and influence of executives' dimission in gem listed companies, Zhejiang university of technology and industry, 2017.6.

[16] J.L. Wang and Z. Zhu, "Empirical research on the relationship between employability of senior executives, salary satisfaction and turnover intention," Journal of lanzhou business school, vol. 2015(1) , pp. 49-57.

[17] W.C. Guo and H.J. Xiao, "Research on the influencing factors of the collective dimission of top management team members of m\&a enterprises -- based on case analysis of jiabao company," Management case study and review, vol. 2011(5), pp. 352-360.

[18] W. Xu and H. Shi, "Executive turnover and lack of corporate culture," Introduction to economic research, vol. 2014(3), pp. 121-122. 